\title{
Academic accommodations for university students living with disability and the potential of universal design to address their needs
}

\author{
Miriam Edwards ${ }^{1}$ (D) $\cdot$ Shiralee Poed ${ }^{2,3}$ (D) Hadeel Al-Nawab ${ }^{3} \cdot$ Olivia Penna $^{3}$
}

Accepted: 1 December 2021 / Published online: 21 January 2022

(C) The Author(s), under exclusive licence to Springer Nature B.V. 2021

\begin{abstract}
This paper reports on a faculty-wide investigation into the experiences of students requiring academic accommodations due to disability. Underpinned by the social model of disability and acceptance that universal design benefits the entire community, this study was conducted at a leading Australian university. A mixed methods approach was used to examine each of the three standard accommodations available: assignment extension, special consideration, and academic adjustment plans. Students living with disability were able to self-identify and to share their experiences relating to these procedures. As a result, data from 493 student survey responses and 9 subsequent follow-on interviews were analysed. At the same time, 10 disability support staff were asked about barriers and enablers faced by students. It was found that most students requiring assistance due to disability, identified as having a 'hidden' disability (learning, cognition or psychiatric conditions). It was also found that accommodations most often related to assessment. While students were most satisfied with academic adjustment plans developed with the support staff, self-perceived notions of stigma associated with disability negatively impacted upon interactions with peers and teaching staff. This study contributes to an emerging body of literature which considers the potential impact universal design might have on the student experience. It is argued that findings are particularly relevant as educators re-imagine university learning and teaching for a post-COVID world.
\end{abstract}

Keywords Universal design · University · Disability · Assessment

Miriam Edwards

miriam.edwards@unimelb.edu.au

1 Williams Centre for Learning Advancement, Faculty of Business and Economics, University of Melbourne, Melbourne, Australia

2 School of Education, University of Queensland, Brisbane, Australia

3 Melbourne Graduate School of Education, University of Melbourne, Melbourne, Australia 


\section{Introduction}

The aim of this study was to better understand the academic needs of university students living with disability so learning and teaching might be designed in a more inclusive manner. Since the provision of support services relies heavily on students self-reporting disability, debate continues as to how universities might best anticipate their needs (Collins et al., 2019). While universal design (CUD, 1997) is increasingly put forward as a promising approach (Dallas et al., 2016; Fleet \& Kondrashov, 2019; Griful-Freixenet et al., 2017), there is sparse evidence as to its impact on the student experience (Rao et al., 2014; Al-Azawei et al., 2016) and little practical advice regarding implementation (Kimball et al., 2016).

With that in mind, this study draws on both the student voice and expertise of disability support staff to further the conversation. Based on a socially responsive model of disability, comments offered by both groups of participants are presented within a universal design framework. While this infers practical actions for designers and educators, it is argued that cultural change is needed in order to reach a sustainable approach to disability and inclusive practice more broadly (Lawrie et al., 2017). It is also proffered that such change is timely given an increasingly diverse student cohort and expanding technological options. By way of contribution, this paper provides support for curriculum designers to embed such strategies proactively rather than relying on reasonable adjustments to address issues relating to disability.

\section{Disability within Australian universities}

University student cohorts are becoming increasingly diverse. This includes more students who are living with disability. Universities Australia's 2019 annual snapshot reported an increase of $123 \%$ in the number of undergraduate domestic students with disability between the years of 2008 and 2017 (UA, 2019). Such trends are not unique to Australia (de Cesarei, 2015; De Los Santos et al., 2019). In the USA, 11.1\% of undergraduate students identified as living with disability during the 2011-2012 enrolment period. That increased to 19.4\% during 2015-2016 (Snyder et al., 2019), while in England, the number of students with a known disability increased $36 \%$ between the academic years of 2014-2015 and 2018-2019 (Hubble \& Bolton, 2020).

Legislation including the Disability Standards for Education 2005 (Cth) specifically supports Australians with disability to participate in higher education. Institutional responses to such legislation can be found in disability action plans (DAPs) published by Australian universities. While DAPs vary in detail, they point to the university's legal responsibility of safeguarding the rights of those (students, staff, visitors) living with disability. DAPs often feature the institution's aspirations toward inclusive practice, describing such intentions as a shared value within their community. At the same time, these plans outline the actions individual students should take if they encounter 
academic difficulties due to disability. According to s. 3.4 of the Disability Standards for Education 2005 (Cth), this includes disclosure of disability by the student, identifying a reasonable adjustment, ${ }^{1}$ and finally applying that to their study in the form of an academic adjustment plan.

Despite these efforts, it can be argued that Australian universities have an unclear view as to the academic challenges students living with disability face. This stance is supported by the generally held belief that disability is under-reported (Brett, 2016; Grimes et al., 2021) and criticism of a reporting mechanism which relies on simplified outdated classifications of disability (Pitman et al., 2021).

To examine these ideas, this study was conducted at a large Australian university made up of metropolitan and rural campuses. It was situated within a faculty comprising of four schools. Those schools offer a range of undergraduate and postgraduate degrees in a variety of disciplines. Many subjects include students from outside the faculty while also attracting a large percentage of international students. At an institutional level, all students may seek assistance through a centralised disability support unit. Because of these factors, both the student perspective and professional insights offered by disability support staff were expected to represent a wide range of experiences. At the same time, this setting may be considered representative of many universities. As such, findings could apply to various faculties within Australian universities and potentially those overseas.

\section{Literature review}

Reasonable adjustments (e.g., as documented within an academic adjustment plan) are an important element in the provision of equitable learning and teaching, but they are indeed responsive to a student's request. Because of this, both the student perspective and the academic culture are commonly examined. The literature points to several challenges facing universities as they address the issue of disability. This includes the complex motivations behind student disclosure (Ehlinger \& Ropers, 2020; Kent et al., 2018), a lack of awareness among teaching staff (Huss \& Eastep, 2016; Podlucká, 2020; Sniatecki et al., 2015), and shortcomings within curriculum design (Everett \& Oswald, 2018; Rao et al., 2015).

The student's disclosure of disability to their university is a highly personal choice, and one which undoubtedly changes over time (Aquino \& Bittinger, 2019). As such, it is understandable that disability is under-reported (Brett, 2016). One explanation is that students are simply unaware of relevant services (Kent et al., 2018; Toutain, 2019). Such unfamiliarity with university procedures is a minor factor, as researchers claim there are darker motives at play. This includes the fear of stigma associated with disability (Black et al., 2015; Cage et al., 2020; Kent et al., 2018); low self-worth (de Cesarei, 2015); uncomfortable feelings around sharing information; lack of experience in self-advocacy (Lightner, et al., 2012); belief a disability would not meet the threshold needed for support (Couzens et al., 2015); the inability to produce appropriate documentation (Toutain, 2019); anticipation that disclosure will not be of benefit; or fear of discrimination (Cage et al., 2020; Couzens et al., 2015; de Cesarei, 2015; Strnadová et al., 2015).

\footnotetext{
1 As defined by the Disability Standards for Education 2005 (Cth), a reasonable adjustment is a measure or action (or a group of measures or actions) taken by an education provider that has the effect of assisting a student with a disability.
} 
Such negative emotions reflect the historically ableist culture of universities (Brown \& Ramlackhan, 2021) while also speaking to the power teaching staff possess. Due to their positions of authority and regular interactions with students, teaching staff are well positioned to become change agents within universities striving to be more inclusive (Ehlinger et al., 2020; Moriña et al., 2020). Yet it is acknowledged they may lack such skills and are often unaware of disability issues (Fleming et al., 2017; Sandoval et al., 2020). As such, related professional development for teaching staff is easily justified (Huss \& Eastep, 2016; Rodesiler \& McGuire, 2015; Sniatecki et al., 2015). It is also argued that teaching staff and curriculum developers should be better supported to create inclusive learning materials (Dallas et al., 2016; Fleet \& Kondrashov, 2019) with universal design commonly referred to as a framework for such efforts (Grier-Reed \& Williams-Wengerd, 2018; Hitch et al., 2015).

\section{Theoretical background}

This study draws on the social model of disability and universal design as theoretical frameworks, both of which are briefly discussed in this section.

\section{The social model of disability}

Disability is a shifting social construct. Today, the social model of disability (Oliver, 1986) is widely accepted. Based on the belief that society should be organised in such a way so as to include all people regardless of ability, it describes impairment only as a difference. As such, the responsibility of removing barriers faced by people with disability belongs to society (Oliver \& Barnes, 2012). This is in sharp contrast to other more traditional models, such as the medical model, which sees disability as a 'medical problem' residing in the individual, and as a result should be dealt with on an individual basis (Evans et al., 2017).

\section{Universal design}

With origins in architectural design, the aim of universal design is to create 'products and environments to be usable by all people, to the greatest extent possible, without the need for adaptation or specialised design' (CUD, 1997). Such a mindset proactively considers the barriers and enablers resulting from diverse populations and by doing so provides solutions which benefit the entire community. Examples of this can be found in everyday situations such as public entry ways which accommodate mobility scooters. These spaces may also assist parents with young children or someone pushing a trolley, while others easily use the space as well.

This study subscribes to the notion that those designing university learning and teaching could take a similar approach. In fact, universal design has been adapted for various educational settings over the years. One such example is universal design for instruction (UDI) (Scott et al., 2003), which is considered particularly relevant for higher education. While successful physical design applications might be encouraging to educators, this study also recognises that universal design does not promise to address all needs. Rather it is a pedagogical model encouraging reflective practice for those wishing to foster an inclusive learning environment (McGuire et al., 2006). 


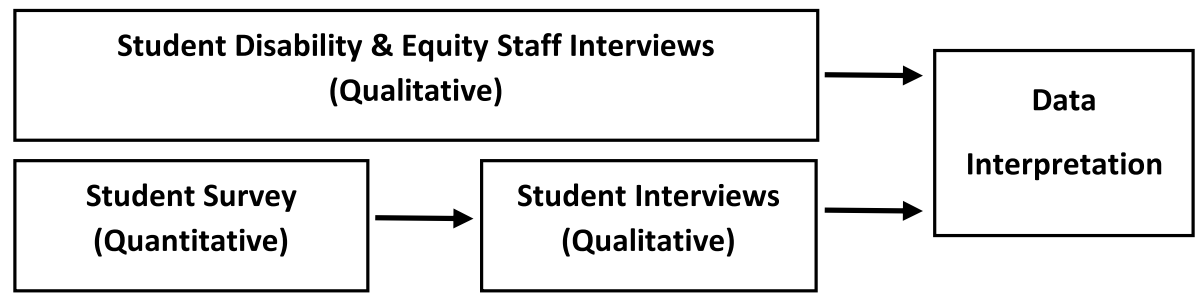

Fig. 1 Embedded research design

\section{Research questions}

The questions for this research were:

What academic accommodations are required for students with disability? With respect to the universal design process, how can these types of academic accommodations be influenced?

\section{Research design}

To investigate the above questions, a mixed methods approach was employed, specifically an embedded design with an emphasis on qualitative data, as shown in Fig. 1. The intention of this research design was to present narratives of those experiencing disability within a university setting and by doing so, address a critical silence within this population (Seale, 2014). As such, importance was placed on participation from both the students requiring academic accommodations due to disability and the professionals supporting them, in this instance the Disability Support Unit (DSU) staff members.

As students require academic accommodations for reasons other than disability, a faculty-wide student survey was used to position this need. The survey provided the mechanism for students to self-identify and to indicate the type(s) of accommodations required. This was complemented by semi-structured student and DSU staff interviews with themes drawing on the broader concepts of barriers and enablers. It was hoped that collectively the responses would describe the effectiveness of academic accommodations provided to students with disability and in doing so identify opportunities for curriculum improvements.

\section{The faculty-wide online student survey}

Student participants were recruited for this study via school-wide emails. The email message included a link to the online survey. Along with the reasons stated earlier, this had the potential of including those not registered with the DSU yet still living with disability. The survey sought responses relating to 3 standard academic accommodations offered to students (see Appendix 1). These included (1) assignment extensions regularly granted by teaching staff, (2) special consideration regarding the student's ability to complete an assessment such as an exam, and (3) academic adjustment plans which are co-created by students and DSU staff. 
Table 1 Student participation in this study

\begin{tabular}{|c|c|c|c|c|c|c|c|}
\hline \multirow[t]{2}{*}{ Description } & \multirow[t]{2}{*}{$N$} & \multicolumn{6}{|c|}{ Percentage } \\
\hline & & of $N$ & of $n^{1}$ & of $n^{2}$ & of $n^{3}$ & of $n^{4}$ & of $n^{5}$ \\
\hline Total respondents & 2075 & & & & & & \\
\hline$n^{1}$ accommodation recipients & 513 & $25 \%$ & & & & & \\
\hline$n^{2}$ included in analysis & 493 & $23.8 \%$ & $96 \%$ & & & & \\
\hline$n^{3}$ interested in interview & 106 & $5.1 \%$ & $20.7 \%$ & $22 \%$ & & & \\
\hline$n^{4}$ prioritised for interview & 38 & $1.8 \%$ & $7.4 \%$ & $7.7 \%$ & $36 \%$ & & \\
\hline$n^{5}$ agreed to interview & 10 & $0.5 \%$ & $1.9 \%$ & $2.0 \%$ & $9.4 \%$ & $26 \%$ & \\
\hline$n^{6}$ total interviewed & 9 & $0.4 \%$ & $1.8 \%$ & $1.8 \%$ & $8.5 \%$ & $23.7 \%$ & $90 \%$ \\
\hline
\end{tabular}

If students attempted the survey but did not report having received any of these accommodations, they were automatically exited from the survey. At the conclusion of the survey, students were asked about their willingness to be interviewed. Those who volunteered were considered by the research team based upon the relevance of their survey responses. Such responses pointed to disability as a motive for seeking academic accommodation(s).

\section{Student interviews}

Purposive sampling (Barratt et al., 2015) was employed to select interviewees from the list of willing participants. These students had described disability as an influencing factor in their request for an assignment extension, special consideration, or an academic adjustment plan. The interviews allowed students to speak about their agency as an adult learner and to offer suggestions as to what might be improved at the school, faculty, or university level (see Appendix 2). Transcripts were provided to all interviewees for accuracy checking, as recommended by Creswell and Miller (2000).

\section{Student participation}

Table 1 illustrates overall student participation through the faculty-wide student survey and individual semi-structured interviews. Although 2,075 students began the survey, only 513 (25\%) indicated they had indeed received one or more accommodation. The other 1,562 (75\%) students were automatically exited from the survey. Within those who had received an academic accommodation, 20 (4\%) did not specify which type and as a result were also excluded. Ultimately, data from 493 students were analysed.

\section{Staff participation}

Following consultation with the DSU Manager, staff participated in two group interviews, each lasting approximately $90 \mathrm{~min}$. The first interview focussed on barriers faced by students with disability, while the second addressed enablers. Ten DSU staff attended both interviews with two staff volunteering for additional individual interviews (see Appendix 
Table 2 Survey coding matrix

\begin{tabular}{lllll}
\hline Disability & Event & Nature of event & Subject of event & $\begin{array}{l}\text { Number } \\
\text { of events }\end{array}$ \\
\hline Mental & Death & Acute & Person & 1 \\
Physical & Illness & Chronic & Family & 2 \\
Learning & Technology & Unspecified & Friend & 3 \\
Unspecified & Group & & Other & \\
& Elite athlete & & Unspecified & \\
& Ineligible & & & \\
& MISC & & & \\
& Unspecified & & & \\
& & & & \\
\end{tabular}

3). Once again, individual interviewees received transcripts for member checking (Creswell \& Miller, 2000).

\section{Data interpretation}

Inductive analysis was used to interpret the student survey and all interview transcripts. This allowed themes to emerge from the frequent and dominant patterns inherent in the raw data (Thomas, 2006). As part of this process, interview comments from both participant groups were aligned to the 9 principles of UDI (Scott et al., 2003). As well as providing a more detailed view of the student experience, this structure provided a way to identify further actions. In addition, the viability of framing faculty or even university-wide strategies around UDI might be considered.

\section{Coding}

A coding framework was developed because several of the questions gathered qualitative data (please see Table 2 Survey coding matrix). Coding for disability was undertaken using several agreed upon trigger words. For example, the code 'Disability-Mental Health' was triggered by responses containing any of the following words: mental, anxiety, mood disorder, or depression. Responses were further coded by the number of adjustments a respondent accessed, the number of reasons, called 'events' for requiring accommodations, the person directly affected by the event (respondent, family member, other), and the nature of the event (acute, chronic, or unspecified). Using Pivot Tables in MS Excel allowed the team to summarise, sort, group, count, and average the data.

\section{Findings}

This study sought to identify what academic accommodations were required by students living with disability and to consider whether a universal design approach might influence that need. Findings are presented for each of the accommodations under consideration (assignment extension, special consideration, and academic adjustment plans) with interview responses aligned to universal design principles. 


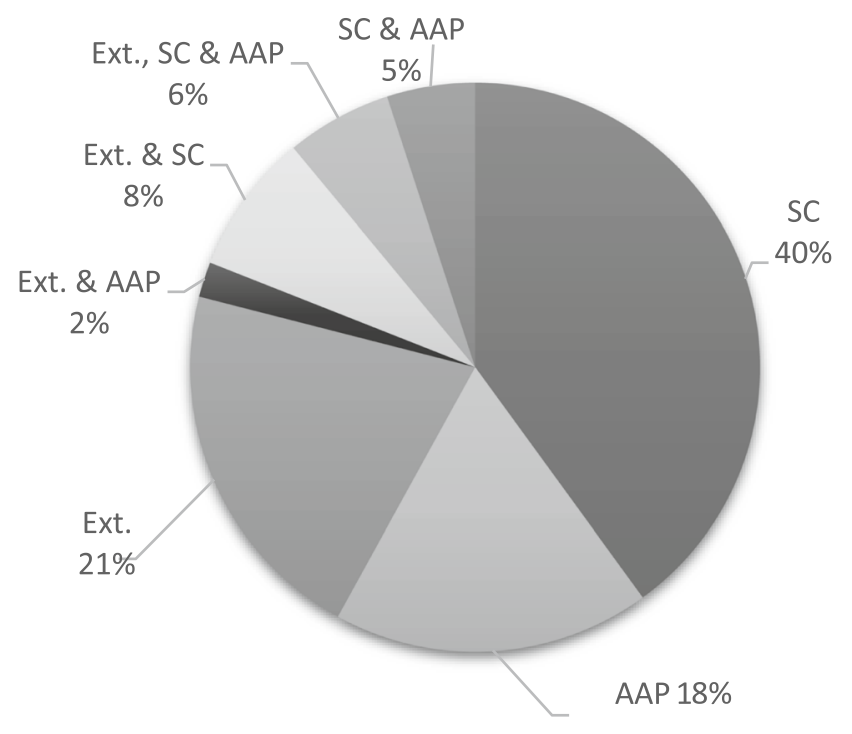

Fig. 2 Breakdown of academic accommodations. Note: AAP academic adjustment plan, Ext assignment extension, SC special consideration. AAP $n=90$; Ext $n=103$; Ext and AAP $n=9$; Ext and SC $n=40$; Ext, SC, and AAP $n=29 ;$ SC $n=199$; SC and AAP $n=23$

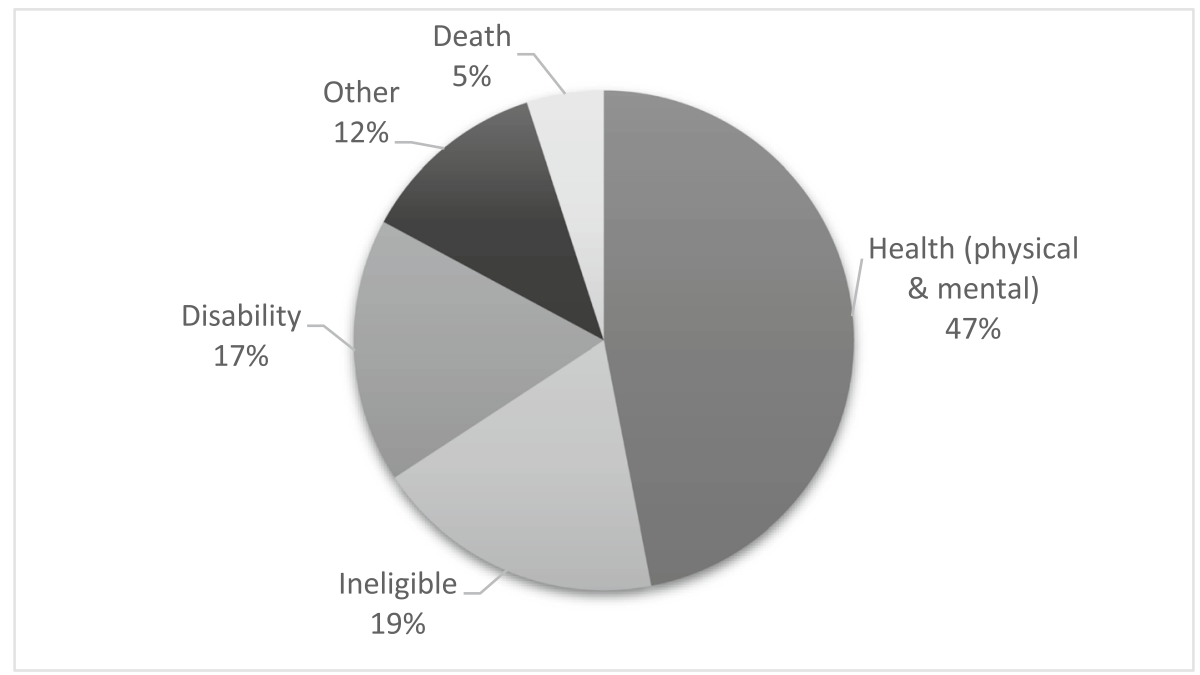

Fig. 3 Reasons students seek assignment extensions. Note: Health $n=85$, ineligible $n=34$, other $n=22$, death $n=9$, disability $n=31$

The majority of respondents were between 18 and 25 years of age (87\%), with $10 \%$ being between 26 and 35 years, 2\% between 36 and 45 years, and only $1 \%$ over 45 years of age. As shown in Fig. 2, of the 493 student responses analysed, 103 (21\%) reported 


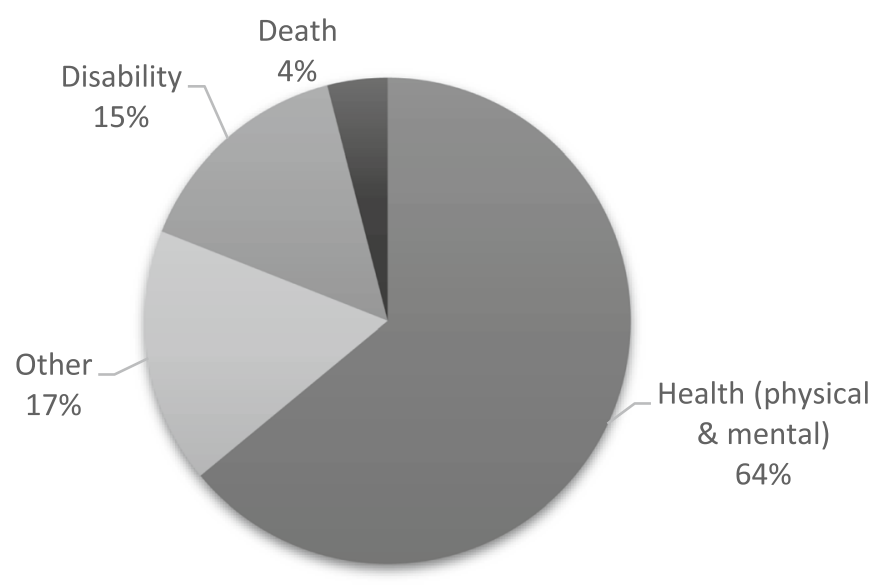

Fig. 4 Reasons students seek special consideration. Note: Health $n=152$, death $n=10$, disability $n=36$, and other $n=40$

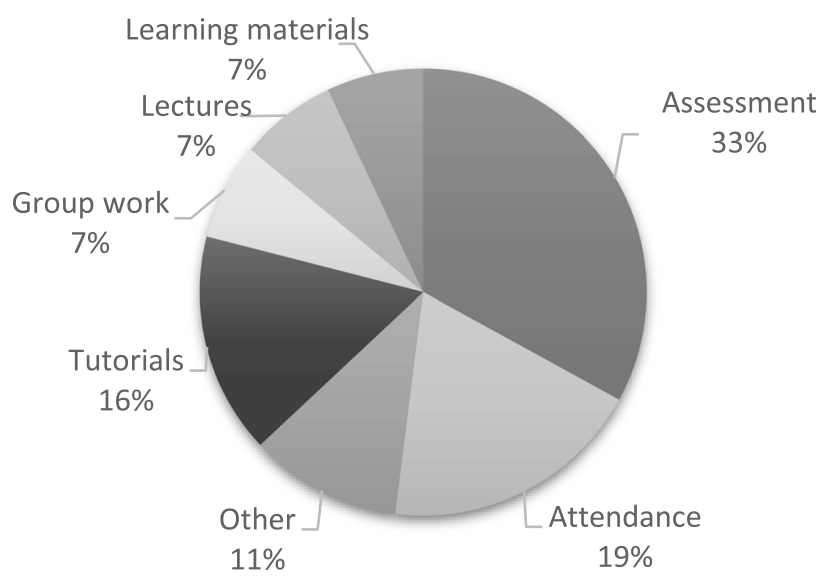

Fig. 5 Reasons students seek academic adjustment plans. Note: Of the 151 students requiring academic adjustment plans, their needs fell into the following categories: assessment $n=50$, learning materials $n=11$, lectures $n=10$, group work $n=10$, tutorials $n=24$, attendance $n=29$, and other $n=17$

receiving a combination of accommodations. In situations where only one of the three options had been selected, special consideration was by far the most common.

\section{Assignment extensions}

As shown in Fig. 3, it was found that almost half of the assignment extension requests were due to health reasons, although it is important to note that assignment extensions could not 
always be granted due to the teaching strategies such as ongoing weekly quizzes or in-class events. Such cases are noted as 'ineligible'.

\section{Special consideration}

This procedure is intended to ensure assessment considers circumstances that adversely impact a student's ability to complete that task. It is typically used for final exams. As shown in Fig. 4, the primary motive was once again health related.

\section{Academic adjustment plans}

In terms of academic adjustment plans, students were given standard categories to select from with the option of providing additional information. As shown in Fig. 5, assessment was the most common motivation. In these cases, students commented that their plan involved such things as alternative exams and assignment extensions.

\section{Student attitudes regarding the effectiveness of academic accommodations}

When asked whether the academic accommodation met their needs, students had very similar feelings toward assignment extensions and special consideration, with positive outcomes reported by $77 \%$ and $78 \%$ of participants respectively. In both cases, $18 \%$ of students felt unsure as to whether their needs were met, while 5\% felt assignment extensions were not helpful, and $4 \%$ said the same about special consideration. Complaints largely focussed on administrative processes and teaching staff being unaware of procedures. Students were more satisfied and decisive when it came to academic adjustment plans, with $93 \%$ stating their needs were met. The remaining $7 \%$ felt their needs were not met. Again, within the small number of students reporting dissatisfaction, administration problems were cited.

\section{Interview responses as they relate to universal design of instruction principles}

The following section presents responses from students and DSU staff as they relate to each of the 9 UDI principles defined below (Scott et al., 2003). Quotes from students are in response to questions about challenges relating to disability, strategies that helped them achieve academically, or suggestions to increase the accessibility of their course (see Appendix 2). Quotes from DSU staff are in response to questions about barriers and enablers faced by students (see Appendix 3).

\section{Equitable use}

Definition: Instruction is designed to be useful to and accessible by people with diverse abilities. Provide the same means of use for all students; identical whenever possible, equivalent when not (Scott et al., 2003).

DSU staff requested all materials given students in face-to-face settings also be placed online. This addresses issues of mobility and sensory loss while assisting students who cannot attend classes for a variety of reasons. The issue of costly supplementary study materials was also raised by staff. Claiming finance is often an issue for students with longterm health issues, they ask that such materials be made freely available online. 
2. Flexibility in use

Definition: Instruction is designed to accommodate a wide range of individual abilities. Provide choice in both instructional methods and learning experiences (Scott et al., 2003).

The DSU staff credited lecture recordings for providing flexibility as well as equity. They noted that some students attend lectures but may not take in information due to conditions such as anxiety. Similarly, a student with traumatic stress disorder commented:

...I would force myself to go to classes. But you may as well not be there because you're [not] learning about content, you're sitting there trying to convince yourself that you're not in any danger, which is horrible.

Another student remarked:

There's this massive conception that... you're too lazy to show up. I want to show up. I love face-to-face learning. I would much rather be in a room with someone than do stuff over the internet. But sometimes that's just not how it's gonna work.

Offering individual flexibility within group work was seen as challenging by the DSU team, with one staff member commenting:

For those who have anxiety or depression or medications or chemo, they can be... as an example, unreliable to the group around them. The whole point is that we don't ever want them to be in a position where they're impacting other students. That doesn't do anything for our cause of normalizing and acceptance.

Similarly a student sharing experiences of hidden disability commented:

... especially when you're working in a group... because of the stigma, and there is definitely still a stigma. Especially for problems that are not outrightly open.

\section{Simple and intuitive}

Definition: Instruction is designed in a straightforward and predictable manner, regardless of the students' experience, knowledge, language skills, or current concentration level. Eliminate unnecessary complexity (Scott et al., 2003).

A student with ADHD (attention-deficit/hyperactivity disorder) said that being able to take small quizzes throughout the semester helped him monitor progress and stay up to date. Another student voiced appreciation for well-organised learning management system (LMS) sites, preloaded with learning materials:

I'm doing statistics and maths and they give at the start of the year all the lecture slides plus a summary sheet for each week which contains all the content for that week with titles and all the formulas and just all the content in like, a summarised form. That's so helpful for me.

These comments align with requests from DSU staff regarding LMS use. Claiming that inconsistency is compounded by disability, they ask for standardisation within teaching sites. 
4. Perceptible information

Definition: Instruction is designed so that necessary information is communicated effectively to the student, regardless of ambient conditions or the student's sensory abilities (Scott et al., 2003).

While the DSU team reported problems with learning materials such as blurry photos, poor colour choices, and non-compliance with WCAG (web content accessibility guidelines) standards, they also spoke of the potentially labour-intensive creation of alternative formats, especially video captioning and transcripts.

\section{Tolerance for errors}

Definition: Instruction anticipates variation in individual student learning pace and prerequisite skills (Scott et al., 2003).

In terms of addressing this principle, both students and DSU staff spoke about the value of providing past exam questions and self-assessment through means such as ungraded multiple choice quizzes. This is also seen as a way to foster exam-preparedness. One DSU staff commented:

Let's focus more on preparing students to take exams - how to get them ready so they aren't sick from stress on the day.

Another staff member added:

Exams affect them, whether it's mental health, whether it's neuro differences. And you know what? It's a hell of a [thing] every faculty has exams of some description, but the majority have options for those who can't or are not best assessed under those conditions.

\section{Low physical effort}

Definition: Instruction is designed to minimize nonessential physical effort in order to allow maximum attention to learning. This includes not only the physical efforts but also the energy that goes into cognitive and decoding tasks (Scott et al., 2003).

Students interviewed had few complaints about physical teaching spaces, although both DSU staff and a student with mobility issues commented on challenges faced with back-to-back classes occurring at opposite ends of the campus. When it came to students' cognitive energy and the decoding of tasks, the DSU team spoke about the usefulness of assessment rubrics to make expectations clear:

Academics and even different tutors may interpret assignment tasks differently from each other. Students get confused, but the tutor says 'I' $m$ the one marking this'. Ambiguity is difficult for those with cognitive issues. This sort of thing may waste a lot of the student's time. 
7. Size and space for approach and use

Definition: Instruction is designed with consideration for appropriate size and space for approach, reach, manipulations, and use regardless of a student's body size, posture, mobility, and communication needs (Scott et al., 2003).

The DSU staff commented that large examination settings can overwhelm students. They reported that in some instances, students spend a considerable amount of time dealing with the anxiety brought on by the setting itself. It was suggested that making students aware of their exam conditions would be helpful.

\section{Community of learners}

Definition: The instructional environment promotes interaction and communication among students and between students and faculty (Scott et al., 2003).

Throughout the interviews comments often aligned to this principle. Issues such as class size, the student's perception of teaching staff, perceived stigma associated with disability, and whether the student was an undergraduate or postgraduate all impacted upon peer and student-to-teacher interactions. One student remarked:

I've felt lesser than my counterparts because of the disability. I've felt that I am being judged as someone who's taking advantage or who is just not putting in an effort, because others don't understand my disability.

The DSU team noted that students may not wish to share an academic adjustment plan with teaching staff. This was consistent with comments from students, for example:

If you do [course name] you can get up to 400 students in the same year level, doing the same subject and I just wasn't sure how to approach them because I feel like, well, they don't know me anyway. Like, they're not gonna remember me, so is there really a point in saying this? But I suppose I would do that differently now.

\section{Instructional climate}

Definition: Instruction is designed to be welcoming and inclusive. High expectations are espoused for all students (Scott et al., 2003).

Elements of this principle also repeated throughout the interviews. While students felt high academic standards are consistently expected, they reported various experiences regarding the instructional climate. This was largely due to assumptions as to how others viewed them:

There is definitely an issue because students don't understand, and when the [teaching staff] aren't supportive... it becomes even more difficult...you have everyone judging you, including the [teacher] who doesn't seem to take it seriously, then that's bad. But on the other hand... A lot of [teaching staff] are very understanding, and they go out of their way to help you. 


\section{Summary of findings}

Assessment is the main reason students who participated in this study sought academic accommodations. These accommodations were most often addressed through special consideration. However, the academic adjustment plans created with DSU staff were seen as more successful than assignment extensions or special consideration when it came to addressing barriers resulting from disability.

Hidden disability was a growing concern among staff, while students reported health (mental or physical) as the main factor driving such requests. Although students rated the services of DSU highly, notions of stigma associated with hidden disability impacted negatively on their interactions with peers and teaching staff. The need to reduce this stigma is further supported by interview responses echoing the importance of an inclusive environment and sense of learning community, two design principles emphasised by the Scott et al. (2003) UDI framework.

\section{Discussion}

Findings from this study confirmed the need for academic accommodations to better serve university students living with disability. It also concurs with previous studies acknowledging the complexities associated with providing such services (Fossey et al., 2017). While student attitudes regarding accommodations offered by disability support staff were largely positive, broader cultural factors such as self-perceived stigma, administrative processes, or attitudes of teaching staff, influenced the student experience. As such, recommendations from students and staff as to how learning and teaching might be more inclusive point to various stakeholders within the university. Because of this, it is suggested institution-wide approaches be considered (Lawrie et al., 2017).

This study commenced at a time when the vast majority of student participants were expected to attend on-campus classes. Since then, COVID-19 has forced many Australian universities online with subsequent efforts made to simultaneously teach local and remote students. While universities might have inched toward similar initiatives in past, it is predicted that such hybrid modes of instruction, are now permanent fixtures (Krishnamurthy, 2020). Practices resulting from this dramatic change have aligned with themes emerging in this study. They include recommendations such as the need for improved and strengthened hybrid delivery models, efficient use of educational technologies, re-imagining of assessment strategies, and a heightened awareness of student mental health.

Educators are beginning to critique COVID-responsive teaching practice as expertise in this area grows (Garris \& Fleck, 2020). While lessons can be learned from decades of online delivery, university educators are advised to think beyond traditional approaches in order to motivate and engage students (Smith \& Kaya, 2021). A variety of recommended strategies point to synchronous and asynchronous interactions (Hodge et al., 2020) which by their very nature may address UDI principles such as equity, flexibility, perceivability, inclusivity, and the fostering of learning communities (Scott et al., 2003). With this in mind, it is proffered that a purposeful application of universal design to both physical and virtual teaching spaces could herald in a new blended approach to university learning (Havens, 2020).

One bright outcome in the otherwise bleak COVID-19 experience has been the extraordinary leveraging of educational technology to engage both on-campus and remote 
students. Take for example the recorded lecture. While teaching staff may have chosen to do this in past, it is now commonly required. In addition to basic expectations, best practice suggests these recordings be provided as short segments purposefully situated within a program of weekly events. While this places more challenges on teaching staff who are already working in a highly disrupted environment (Watermeyer et al., 2021), they might consider it time well-spent, particularly if the recordings are popular among students. They may also enlist the support of professional services within the university to deliver the final product. This approach speaks to one type of adjustment previously organised by disability support staff. Some universities are now going one step further by offering on-campus lectures which are live-streamed as well as recorded.

Assessment within the time of COVID-19 has produced additional challenges for students, teaching staff, and administrators alike. While existing concerns included designing authentic assessment and ensuring academic integrity (Ellis et al., 2020), remote and hybrid delivery models have further complicated these issues. It is argued that academic stresses such as computer anxiety (Garris \& Fleck, 2020) exacerbate mental health issues already experienced due to COVID-19. Such difficulties are recognised by university leaders as well. When asked in early 2020 about priorities, American college and university presidents rated mental health of students as their number one concern (Lederman, 2020).

The goal of being an inclusive university while relying on individualised reactive strategies to support students with disability seems impractical at best. Yet the gap between these two notions is magnified as universities increasingly refer to universal design within DAPs. As a result, practical frameworks such as UDI are needed to identify actions and support institution-wide conversations. Such an approach could lessen apprehensions held by teaching staff (Watermeyer et al., 2021) and address barriers such as stigma around hidden disabilities, which cannot be remedied by academic accommodations.

\section{Limitations of this study}

All students participating in this study were from the same faculty. As such, there were some limitations regarding the types of teaching strategies under consideration. This study did not include teaching staff or curriculum designers.

\section{Conclusion}

Given the increasingly diverse university cohort, it is argued that a proactive approach to disability is needed. Within this study, students and support staff described the types of academic accommodations needed by students living with disability. By doing so, they identified strategies that could increase the inclusivity of university courses. In many instances, their suggestions aligned with ongoing efforts to overcome learning and teaching challenges due to COVID-19 restrictions. This included assessment design and flexible attendance requirements. Considered a growing concern due to the current pandemic, mental health issues are also featured in this study.

As the phrase 'universal design' is appearing more often in Australian university DAPs, studies focussing on policy would be of interest. Strategies which enable individual principles of UDI and the outcomes they produce could be investigated further. For example; 
flexibility, perceivability, or community of learners (Scott et al., 2003). The impact of such approaches within assessment design deserves consideration. Perspectives of various stakeholders, including teaching staff and university leaders also warrants further investigation.

It is suggested that as universities plan for a future which addresses these challenges, an institutional approach is needed. This study contributes to a growing body of literature promoting universal design as one such approach. By drawing on the experiences of disability support staff and students, it suggests that UDI principles may provide a structure for reimagining education in a post-COVID world.

\section{Appendix 1 Students' survey}

\section{Introduction}

I have read the attached plan language statement (mandatory response).

Standard demographic block (optional responses about age, gender).

Identification of the school students are enrolled in (optional response).

\section{Additional academic support}

During your time as a student, did you receive any additional support through an extension, special consideration or academic adjustment plan?

If the student answered 'No' they were automatically removed from the survey. If the student responded 'Yes', the next question appeared:

I received the following (please select all appropriate items) Extension, Special consideration, Academic adjustment plan.

\section{Extensions}

If the student indicated having received an extension, the following questions were presented.

Why did you apply for an extension?

Did the extension address your needs?

Is there anything you wish to say about the extension?

\section{Special consideration}

If the student indicated having received special consideration, the following questions were presented.

Why did you apply for special consideration?

Did the special consideration address your needs?

Is there anything you wish to say about the special consideration? 
3. Academic adjustment plan

If the student indicated having an academic adjustment plan, the following questions were presented.

I received the following academic adjustment(s) for my subjects (multiple responses accepted):

Attendance, Assessment, Learning materials, Lectures, Group or peer work, Tutorials, Other.

If you selected 'other'. Please describe.

Did the academic adjustment for your learning material address your needs? Please explain.

Is there anything you wish to say about your plan?

\section{Survey conclusion}

I would be interested in participating in a 30-min follow-up interview to discuss these questions further.

If yes, we require an email address. This will remain confidential.

\section{Appendix 2 Interview themes-students}

What aspects of your study did you find challenging, particularly as they related to needs arising from disability?

What strategies do you feel have helped you to succeed as a student?

If you have a current academic adjustment plan or have had one in past, did you share that plan with your academic/tutor? Why?/Please tell us about that experience.

Did you apply for special consideration? If so, please tell us about your experience.

Knowing what you now know about studying within the faculty, what would you do differently?

If you could make a change to the way your course was offered in order to make it more accessible, what would that be?

Is there anything we haven't spoken about in terms of your experience as a student that you would like to share?

\section{Appendix 3 Interview themes- disability support unit staff}

Interview 1 focussed on barriers. The thematic questions included:

What do you feel are the most challenging aspects for students with disability?

When you create an academic adjustment plan for students with disability, are there generic adjustments you typically record?

Are there any specific adjustments that are needed by students that are not generally needed by students with disability in other faculties or schools?

What factors do you feel impact on a student's decision around sharing their academic adjustment plan with academics? 
Interview 2 focussed on enablers. The thematic questions included:

Are there things academics could do differently to make subjects more accessible in terms of... Learning materials, Teaching/delivery methods, Assessment strategies?

What factors do you feel impact on a student's decision around sharing their academic adjustment plan with academics?

What strategies would you like to see students using?

Is there anything we haven't spoken about in terms of your experience supporting students that you would like to share?

Author contribution All authors contributed to the study conception and design. The revised draft of this manuscript was written by Miriam Edwards and all authors who contributed to previous versions. All authors read and approved the final manuscript.

Funding Partial funding support was received through a teaching and learning grant provided by a faculty within the university where this study was undertaken.

Data Availability Not applicable.

Code availability Not applicable.

\section{Declarations}

Ethics approval Institutional ethics approval was formally granted for this project.

Consent to participate Not applicable.

Consent for publication The authors give permission for publication.

Competing interests The authors declare no competing interests.

Additional declarations for articles in life science journals that report the results of studies involving humans and/or animal Not applicable.

\section{References}

Al-Azawei, A., Serenelli, F., \& Lundqvist, K. (2016). Universal design for learning (UDL): A content analysis of peer-reviewed journal papers from 2012 to 2015. Journal of the Scholarship of Teaching \& Learning, 16(3), 39-56. https://doi-org.ezp.lib.unimelb.edu.au/https://doi.org/10.14434/josotl.v16i3. 19295

Aquino, K. C., \& Bittinger, J. D. (2019). The self-(un) identification of disability in higher education. Journal of Postsecondary Education and Disability, 32(1), 5-19. https://eric.ed.gov/?id=EJ1217454

Barratt, M. J., Ferris, J. A., \& Lenton, S. (2015). Hidden populations, online purposive sampling, and external validity: Taking off the blindfold. Field Methods, 27(1), 3-21. https://doi.org/10.1177/1525822X14 526838

Black, D. R., Weinberg, L. A., \& Brodwin, M. G. (2015). Universal design for learning and instruction: Perspectives of students with disabilities in higher education. Exceptionality Education International, 25(2), 1-26. https://doi.org/10.5206/eei.v25i2.7723

Brett, M. (2016). Disability and Australian higher education: Policy drivers for increasing participation. In A. Harvey, C. Burnheim \& M. Brett (Eds.), Student equity in Australian higher education: Twenty-five years of a fair chance for all (pp. 87-108). Springer. https://doi.org/10.1007/978-981-10-0315-8_6 
Brown, N., \& Ramlackhan, K. (2021). Exploring experiences of ableism in academia: A constructivist inquiry. Higher Education: The International Journal of Higher Education Research, 1-15. Advance online publication. https://doi.org/10.1007/s10734-021-00739-y

Cage, E., Stock, M., Sharpington, A., Pitman, E., \& Batchelor, R. (2020). Barriers to accessing support for mental health issues at university. Studies in Higher Education, 45(8), 1637-1649. https://doi.org/10. $1080 / 03075079.2018 .1544237$

Centre for Universal Design (CUD). 1997. The principles of universal design, version 2.0 - 4/1/97 North Carolina State University. Retrieved January 12, 2020 from, https://projects.ncsu.edu/ncsu/design/cud/ about_ud/udprinciplestext.htm

Collins, A., Azmat, F., \& Rentschler, R. (2019). "Bringing everyone on the same journey": Revisiting inclusion in higher education. Studies in Higher Education, 44(8), 1475-1487. https://doi.org/10.1080/ 03075079.2018.1450852

Couzens, D., Poed, S., Kataoka, M., Brandon, A., Hartley, J., \& Keen, D. (2015). Support for students with hidden disabilities in universities: A case study. International Journal of Disability, Development and Education, 62(1), 24-41. https://doi.org/10.1080/1034912X.2014.984592

Creswell, J. W., \& Miller, D. L. (2000). Determining validity in qualitative inquiry. Theory into Practice, 39(3), 124-130. https://doi.org/10.1207/s15430421tip3903_2

Dallas, B. K., Sprong, M. E., \& Kluesner, B. K. (2016). Multi-university comparison of faculty attitudes and use of universal design instructional techniques. Rehabilitation Research, Policy, and Education, 30(2), 148-160. https://doi.org/10.1891/2168-6653.30.2.148

de Cesarei, A. (2015). Psychological factors that foster or deter the disclosure of disability by university students. Psychological Reports, 116(3), 665-673. https://doi.org/10.2466/15.PR0.116k26w9

De Los Santos, S. B., Kupczynski, L., \& Mundy, M.-A. (2019). Determining academic success in students with disabilities in higher education. International Journal of Higher Education, 8(2), 16-38.

Disability Standards for Education 2005 (Cth). S. 3.4 (Austl.). https://www.legislation.gov.au/Details/ F2005L00767

Ehlinger, E., \& Ropers, R. (2020). "It's All About Learning as a Community": Facilitating the Learning of Students With Disabilities in Higher Education Classrooms. Journal of College Student Development, 61(3), 333-349.

Ellis, C., van Haeringen, K., Harper, R., Bretag, T., Zucker, I., McBride, S., Rozenberg, P., Newton, P., \& Saddiqui, S. (2020). Does authentic assessment assure academic integrity? Evidence from contract cheating data. Higher Education Research \& Development, 39(3), 454-469. https://doi.org/10. 1080/07294360.2019.1680956

Evans, N. J., Broido, E. M., Brown, K. R., \& Wilke, A. K. (2017). Disability in higher education: A social justice approach. John Wiley \& Sons.

Everett, S., \& Oswald, G. (2018). Engaging and training students in the development of inclusive learning materials for their peers. Teaching in Higher Education, 23(7), 802-817.

Fleet, C., \& Kondrashov, O. (2019). Universal design on university campuses: A literature review. Exceptionality Education International, 29(1), 136-148. https://ojs.lib.uwo.ca/index.php/eei/article/view/ 11125

Fleming, A. R., Oertle, K. M., \& Plotner, A. J. (2017). Student voices: Recommendations for improving postsecondary experiences of students with disabilities. Journal of Postsecondary Education and Disability, 30(4), 309-326. https://files.eric.ed.gov/fulltext/EJ1172798.pdf

Fossey, E., Chaffey, L., Venville, A., Ennals, P., Douglas, J., \& Bigby, C. (2017). Navigating the complexity of disability support in tertiary education: Perspectives of students and disability service staff. International Journal of Inclusive Education, 21(8), 822-832. https://doi.org/10.1080/13603 116.2017.1278798

Garris, C. P., \& Fleck, B. (2020). Student evaluations of transitioned-online courses during the COVID19 pandemic. Scholarship of Teaching and Learning in Psychology. Advance online publication https://doi.org/10.1037/st10000229

Grier-Reed, T., \& Williams-Wengerd, A. (2018). Integrating universal design, culturally sustaining practices, and constructivism to advance inclusive pedagogy in the undergraduate classroom. Education Sciences, 8(4), 167-181. https://doi.org/10.3390/educsci8040167

Griful-Freixenet, J., Struyven, K., Verstichele, M., \& Andries, C. (2017). Higher education students with disabilities speaking out: Perceived barriers and opportunities of the universal design for learning framework. Disability \& Society, 32(10), 1627-1649. https://doi.org/10.1080/09687599.2017. 1365695

Grimes, S., Southgate, E., Scevak, J., \& Buchanan, R. (2021). Learning impacts reported by students living with learning challenges/disability. Studies in Higher Education, 46(6), 1146-1158. https://doi. org/10.1080/03075079.2019.1661986 
Havens, G. (2020). Universal design in the age of COVID-19: Changes are demanding that campuses include all learners. Planning for Higher Education, 48(4), 14. https://go.gale.com/ps/i.do?id= GALE\%7CA652743063\&sid=googleScholar\&v=2.1\&it=r\&linkaccess $=$ abs\&issn=07360983\&p= AONE\&sw $=$ w\&userGroupName $=$ anon $\% 7 E d 4 d b 9 e c 8$

Hitch, D., Macfarlane, S., \& Nihill, C. (2015). Inclusive pedagogy in Australian universities: A review of current policies and professional development activities. International Journal of the First Year in Higher Education., 6(1), 135-145. https://doi.org/10.5204/intjfyhe.v6i1.254

Hodge, C., Moore, S., Lockee, B., Trust, T., \& Bond, A. (2020, March 27). The difference between emergency remote teaching and online learning. Educause. https://er.educause.edu/articles/2020/3/ the-difference-between-emergency-remote-teaching-and-online-learning

Hubble, S. \& Bolton, P. (2020). House of Commons Library: Briefing paper, Number 8716, 28 July 2020: Support for disabled students in higher education in England. https://commonslibrary.parli ament.uk/research-briefings/cbp-8716/

Huss, J. A., \& Eastep, S. (2016). Okay, our courses are online, but are they ADA compliant? An investigation of faculty awareness of accessibility at a midwestern university. Inquiry in Education, 8(2), 2. https://eric.ed.gov/?id=EJ1171774

Kent, M., Ellis, K., \& Giles, M. (2018). Students with disabilities and eLearning in Australia: Experiences of accessibility and disclosure at Curtin University. TechTrends: Linking Research and Practice to Improve Learning, 62(6), 654. https://doi.org/10.1007/s11528-018-0337-y

Kimball, E. W., Wells, R. S., Ostiguy, B. J., Manly, C. A., \& Lauterbach, A. A. (2016). Students with disabilities in higher education: A review of the literature and an agenda for future research. In $\mathrm{M}$. Paulsen (Ed.), Higher Education: Handbook of Theory and Research (pp. 91-156). Springer.

Krishnamurthy, S. (2020). The future of business education: A commentary in the shadow of the Covid19 pandemic. Journal of Business Research, 117, 1-5. https://doi.org/10.1016/j.jbusres.2020.05. 034

Lawrie, G., Marquis, E., Fuller, E., Newman, T., Qiu, M., Nomikoudis, M., Roelofs, F., \& Van Dam, L. (2017). Moving towards inclusive learning and teaching: A synthesis of recent literature. Teaching \& Learning Inquiry, 5(1), 1-13. https://doi.org/10.20343/5.1.3

Lederman, D (2020, March 27). Presidents fear financial, and human, toll of coronavirus. Inside Higher Ed. https://www.insidehighered.com/news/survey/college-presidents-fear-financial-and-human-tollcoronavirus-their-campuses

Lightner, K. L., Kipps-Vaughan, D., Schulte, T., \& Trice, A. D. (2012). Reasons university students with a learning disability wait to seek disability services. Journal of Postsecondary Education and Disability, 25(2), 145-159. https://eric.ed.gov/?id=EJ994283

McGuire, J. M., Scott, S. S., \& Shaw, S. F. (2006). Universal design and its applications in educational environments. Remedial \& Special Education, 27(3), 166-175. https://doi.org/10.1177/0741932506 0270030501

Moriña, A., Sandoval, M., \& Carnerero, F. (2020). Higher education inclusivity: When the disability enriches the university. Higher Education Research \& Development, 1-15https://doi.org/10.1080/ 07294360.2020 .1712676

Oliver, M. (1986). Social policy and disability: Some theoretical issues. Disability, Handicap \& Society, 1(1), 5-17. https://doi.org/10.1080/02674648666780021

Oliver, M., \& Barnes, C. (2012). The new politics of disablement. Macmillan International Higher Education.

Pitman, T., Brett, M., \& Ellis, K. (2021). Three decades of misrecognition: Defining people with disability in Australian higher education policy. Disability \& Society, 1-19https://doi.org/10.1080/09687 599.2021.1937061

Podlucká, D. (2020). Transformative anti-ableist pedagogy for social justice: Charting a critical agenda for inclusive education. Outlines: Critical Practice Studies, 21(1), 69-97.

Rao, K., Edelen-Smith, P., \& Wailehua, C. U. (2015). Universal design for online courses: Applying principles to pedagogy. Open Learning: The Journal of Open, Distance and e-Learning, 30(1), 35-52. https://doi.org/10.1080/02680513.2014.991300

Rao, K., Ok, M. W., \& Bryant, B. R. (2014). A review of research on universal design educational models. Remedial and Special Education, 35(3), 153-166. https://doi.org/10.1177/0741932513518980

Rodesiler, C. A., \& McGuire, J. M. (2015). Ideas in practice: Professional development to promote universal design for instruction. Journal of Developmental Education, 38(2), 24-31. https://www.jstor. org/stable/24614043

Sandoval, M., Morgado, B., \& Doménech, A. (2020). University students with disabilities in Spain: Faculty beliefs, practices and support in providing reasonable adjustments. Disability \& Society, 1-20https://doi.org/10.1080/09687599.2020.1751078 
Scott, S., McGuire, J., \& Shaw, S. (2003). Universal design for instruction - A new paradigm for adult instruction in postsecondary education. Remedial and Special Education, 24(6), 369-379. https:// doi.org/10.1177/07419325030240060801

Seale, J. (2014). E-learning and disability in higher education: Accessibility research and practice (2nd ed.). Routledge.

Smith, E. S., \& Ece Kaya, E. (2021). Online university teaching at the time of COVID-19 (2020): An Australian perspective. IAFOR Journal of Education, 9(2), 183-200. https://doi.org/10.22492/ije.9. 2.11

Sniatecki, J., Perry, H., \& Snell, L. (2015). Faculty attitudes and knowledge regarding college students with disabilities. Journal of Postsecondary Education and Disability, 28(3), 257-295. https://files. eric.ed.gov/fulltext/EJ1083837.pdf

Snyder, T.D., de Brey, C., \& Dillow, S.A. (2019). Table 311.10. Number and percentage distribution of students enrolled in postsecondary institutions, by level, disability status, and selected student characteristics: 2015-2016. In Digest of Educational Statistics 2017 (53 ${ }^{\text {rd }}$ ed.; NCES 2018-070). National Center for Education Statistics, Institute of Education Sciences, U.S. Department of Education. http://nces.ed.gov/pubs2018/2018070.pdf

Strnadová, I., Hájková, V., \& Květoňová, L. (2015). Voices of university students with disabilities: Inclusive education on the tertiary level-A reality or a distant dream? International Journal of Inclusive Education, 19(10), 1080-1095. https://doi.org/10.1080/13603116.2015.1037868

Thomas, D. R. (2006). A general inductive approach for analyzing qualitative evaluation data. American Journal of Evaluation, 27, 237-246. https://doi.org/10.1177/1098214005283748

Toutain, C. (2019). Barriers to accommodations for students with disabilities in higher education: A literature review. Journal of Postsecondary Education and Disability, 32(3), 297-310.

Universities Australia [UA]. (2019). Data snapshot 2019 Final Report. https://www.universitiesaustralia. edu.au/wpcontent/uploads/2019/06/Data-snapshot-2019-FINAL.pdf

Watermeyer, R., Crick, T., Knight, C., \& Goodall, J. (2021). COVID-19 and digital disruption in UK universities: Afflictions and affordances of emergency online migration. Higher Education: The International Journal of Higher Education Research, 81(3), 623-641. https://doi.org/10.1007/s10734-020-00561-y

Publisher's Note Springer Nature remains neutral with regard to jurisdictional claims in published maps and institutional affiliations. 